\title{
TheGMS
}

\section{Flavonoids from Carica papaya Linn. against SARS-CoV-2 protease: Molecular Docking and ADME analysis}

\author{
Sameer Sharma ${ }^{1}$ and Sibi $\mathrm{G}^{1^{*}}$ \\ ${ }^{1}$ Department of Biotechnology, Indian Academy Degree College-Autonomous, Bangalore \\ Address for correspondence: \\ ${ }^{*}$ Corresponding Author: Sibi G, Head of the Department, Department of Biotechnology, Indian Academy Degree College- Autonomous, Bangalore. \\ Email: gsibii@gmail.com \\ Submitted: $5^{\text {th }}$ May 2020 \\ Approved: 12 May 2020 \\ Published: 15 May 2020 \\ How to cite this article: Sharma S, Sibi G. Flavonoids from Carica papaya Linn. against SARS-CoV-2 protease: Molecular Docking \\ and ADME analysis. G Med Sci. 2020; 1(1): 037-046. https://www.doi.org/10.46766/thegms.biotech.20050701 \\ Copyright: @ 2020 Sibi G, et al. This is an open access article distributed under the Creative Commons Attribution License, which permits unrestricted \\ use, distribution, and reproduction in any medium, provided the original work is properly cited.
}

\section{ABSTRACT}

Objective: The objective of the study is to investigate the inhibitory activity of selected flavonoids from the plant Carica Papaya Linn. using molecular docking against SARS-CoV-2 or Covid-19.

Methodology: In silico bioinformatics tools was used to investigate the capabilities of flavonoids as an acclamatory inhibitor of Covid-19. The 3D structure of the receptor was retrieved from PDB and of the ligands from PubChem databases. Docking analysis of the selected compounds was performed employing Autodock and PyRx. Further investigation of the Phytoligands were predicted using Lipinski filter and SwissADME online server. Results: All the compounds are non-violated according to the Lipinski's parameters and making them capable for biological activities. As a result, Quercetin has highest binding affinity and score followed by apigenin and luteolin and expected to be effective in Covid-19 treatment.

\section{Introduction}

Coronavirus disease, caused by the Severe acute respiratory syndrome -2 (SARS-CoV-2), is in the center of worldwide concern since December 2019 [1]. Coronavirus belongs to the family Coronaviridae[2] and are single stranded RNA virussurrounded by an envelope protein. SARS- $\mathrm{CoV}$ is zoonotic in origin because they cause severe respiratory syndrome [3]. Patients infected with SARS-CoV-2 have a wide range of symptoms such as fever, cough and shortness of breathing [4]. It has also reported that about $2-10 \%$ of the infected persons with covid-19 had gastrointestinal symptoms like vomiting, diarrhea and abdominal pain [4,5]. SARS-CoV and MERS-CoV outcome from severe public health issues which ultimately lead to epidemics resulting in important loss of life [6-8]. There are currently no vaccines available for the prevention \& treatment of Coronavirus disease $[9,6]$.

Plant derived compounds always remain a momentous source for the expansion of novel anti-viral agents. Currently, there are still no effective cure that target the coronavirus backbone and the development of these medicines or treatments requires months and years, so we should be oriented towards treatments of natural origin based on aromatic and medicinal plants to have the compounds having the ability to inhibit COVID19 [10].Carica papaya, commonly known as papaya is an herbaceous plant. Carica papaya is normally used in fever, pyrexia, diabetes, gonorrhea, synphilis [11-13]. The main group of phytochemicals in Carica papaya is flavonoids, which includes the Luteolin, 
Apigenin, Quercetin, Kaempferol, and Benzylglucosinolate. From the listed flavonoids, 5 were selected based on PASS (Prediction of Active Spectra for Substances) online server prediction [14] which are used to find the biological activities of the particular compounds.In our study, we made a selection of the plants studied based on two principles: the first is oral efficacy, this means that the majority of papaya plants should be absorbable by the oral route, the second principle is the compatibility of traditional use, then we used molecular docking to have the compounds having an anticoronavirus effect by fighting on several criteria.

\section{Methodology}

\section{Receptor selection}

The 3D crystal structure of covid-19 main protease was retrieved from PDB (Protein Data Bank). PDB ID: 6M03www. rcsb.org [15].

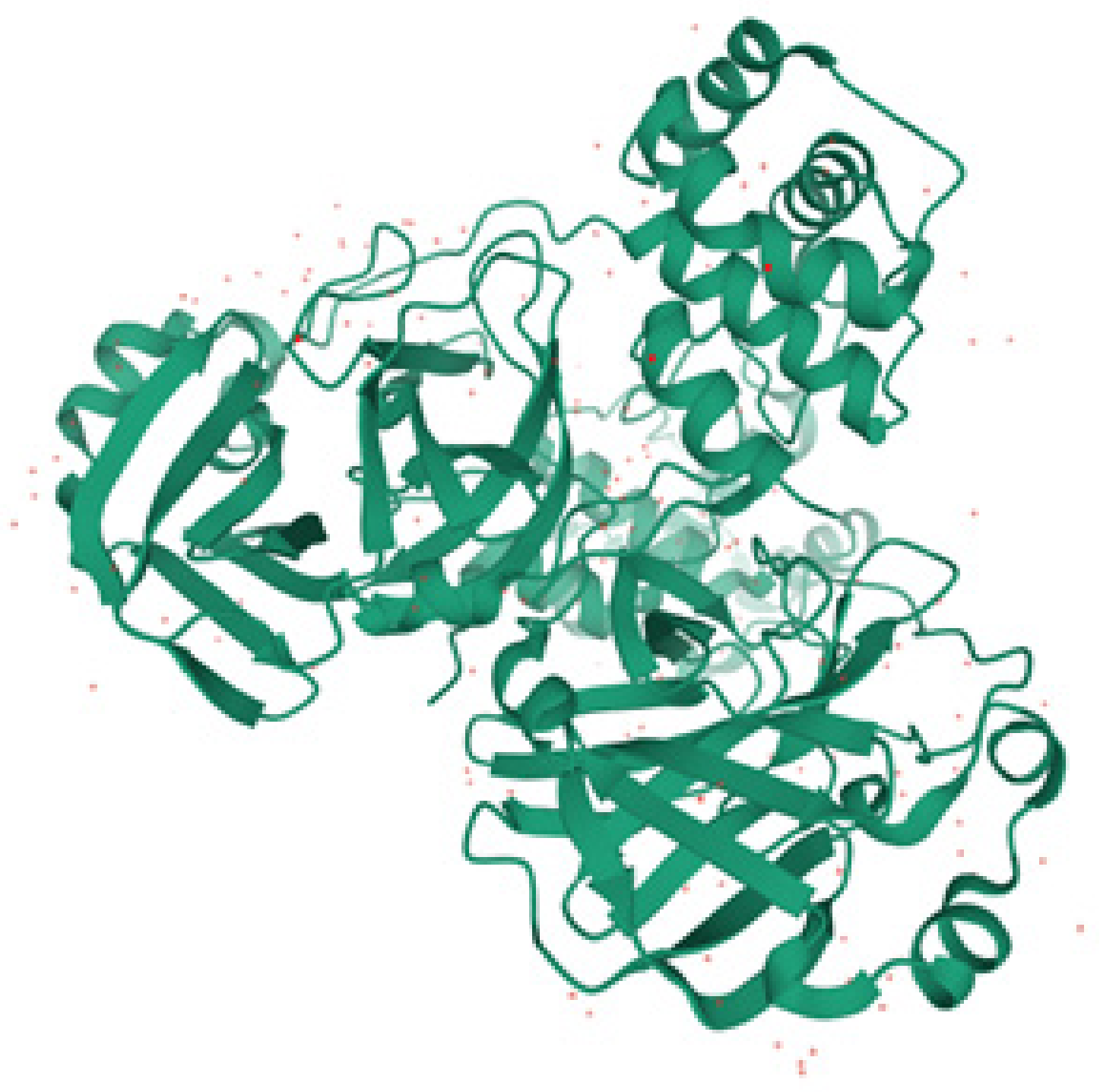

Fig 1: Crystal structure of covid-19 main protease

\section{Phytoligands preparation}

All the selected ligand files were retrieved from PubChem database in SDF (Structured Data format). All selected compounds i.e. Luteolin, Apigenin, Quercetin, Kaempferol, Benzylglucosinolate [16-20] and analyzed using Marvin view [21]. And then all SDF files converted into PDB file using PyMol version 1.3 [22]. 


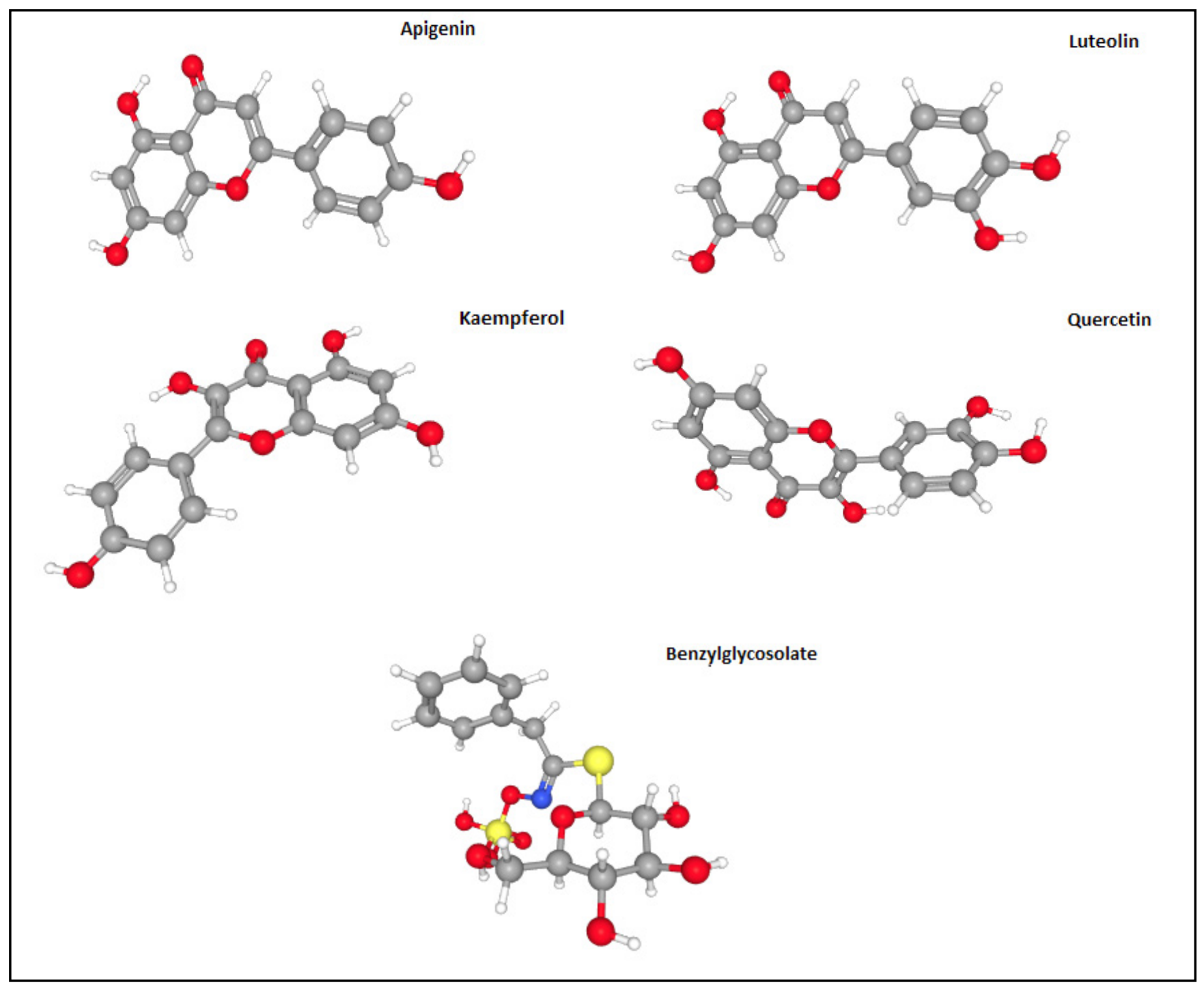

Fig 2: 3D-structure of selected ligands from Carica papaya Linn

\section{Drug likeness analysis}

The likeness prediction of drug was carried out through Lipinski filter. According to Lipinski filter, some criteria must fulfill like molecular mass, hydrogen donor and acceptor, cLogP and molar refractive index [23]. Lazar an online server was used to assume or predict the best selected compounds using virtual docking (http://lazar.in-silico.de/predict).

\section{ADMET analysis}

The physiological properties were investigated by SWISS ADME, which is noted as a best tool in drug discovery [24]. And this analyzes refers to adsorption, distribution, metabolism and excretion. GI absorption and brain barrier access are two main pharmacological access in drug discovery processes.

\section{BOILED-Egg}

BOILED-Egg is used to predict depend on gastrointestinal absorption and brain barrier for the development of drugs. According to BOILED-Egg plot, if any compounds are rightfully placed in white region of eggs, the probability of GI absorption is higher and brain barrier is higher in case of compound correctly placed in yellow region. In this study, the analysis of the selected compounds for BOILED-Egg was done using SwissADME server [25]. 


\section{Molecular Docking simulation}

The aim of the docking simulation is to assume or predict the binding modes of the respective ligands. In molecular docking, the docking score or binding affinity, ranking all the binding poses of the molecule, accordingly. Further, all the ligands were docked with the target receptors PDB ID: 6M03 using PyRX[26] and Autodock. Once the docking was performed, all the hydrophobic interaction was investigated using PyMol version 1.3 [22].

\section{Results}

\section{Drug likeness analysis}

Results of drug likeness investigation using Lipinski filter explains the rigidity of all selected compounds which can be considered for drug design.

Table 1: Lipinski filter analysis

\begin{tabular}{|c|c|c|c|c|c|}
\hline Ligands & $\begin{array}{c}\text { Molecular } \\
\text { weight }\end{array}$ & $\begin{array}{c}\text { Hydrogen bond } \\
\text { donor }\end{array}$ & $\begin{array}{c}\text { Hydrogen bond ac- } \\
\text { ceptor }\end{array}$ & cLogP & Molar refractivity \\
\hline Luteolin & $\begin{array}{c}286.24 \mathrm{~g} / \\
\mathrm{mol}\end{array}$ & 4 & 6 & 1.73 & 76.01 \\
\hline Apigenin & $\begin{array}{c}270.24 \mathrm{~g} / \\
\mathrm{mol}\end{array}$ & 3 & 5 & 2.11 & 73.99 \\
\hline Quercetin & $\begin{array}{c}302.23 \mathrm{~g} / \\
\mathrm{mol}\end{array}$ & 5 & 7 & 1.23 & 78.04 \\
\hline Kaempferol & $\begin{array}{c}286.24 \mathrm{~g} / \\
\mathrm{mol}\end{array}$ & 4 & 6 & 1.58 & 76.01 \\
\hline Benzylglucosinolate & \begin{tabular}{c}
$409.4 \mathrm{~g} / \mathrm{mol}$ \\
\hline
\end{tabular} & 5 & 11 & -0.61 & 91.57 \\
\hline
\end{tabular}

According to Drug design criteria, the above table shows that the selected ligands were noted to be in acceptable criteria.

\section{AdmetSAR analysis}

Table 2: ADME prediction

\begin{tabular}{|c|c|c|c|c|}
\hline Ligands & GI absorption & Blood brain barrier & p-GP substrate & $\begin{array}{c}\text { Subcellular localiza- } \\
\text { tion }\end{array}$ \\
\hline Luteolin & High & No & No & Mitochondria \\
\hline Apigenin & High & No & No & Mitochondria \\
\hline Quercetin & High & No & No & Mitochondria \\
\hline Kaempferol & High & No & No & Mitochondria \\
\hline Benzylglucosinolate & Low & No & No & Mitochondria \\
\hline
\end{tabular}

Interestingly, the selected ligands don't show any toxicity which justify to considered or screen the natural compounds. 


\section{BOILED-Egg Plot}

The prediction reveals that the except Benzylglucosinolate, all the compounds has high GI absorption such as luteolin, apigenin, quercetin and kaempferol.

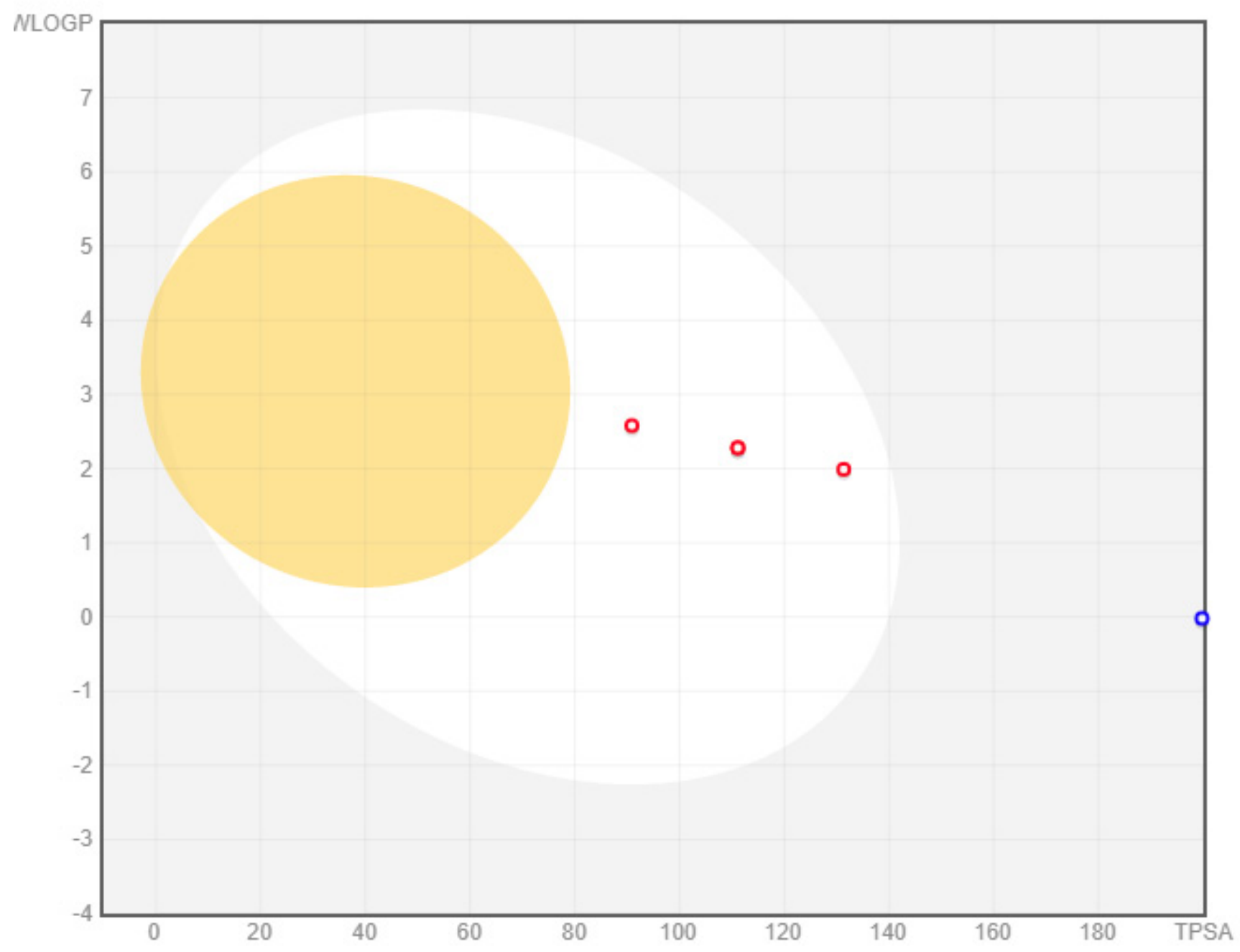

Fig 3: BOILED-Egg Plot

According to BOILED-Egg model, the white region is defined as the physicochemical space of molecules with highest probability of being absorbed by GI tract and yellow region defined as the space of molecules with highest probability to interact with brain barrier.

\section{Molecular Docking Simulation}

Results observed from molecular docking process of all selected ligands with receptor (covid-19) showing better docking score and binding affinity. This prediction of compounds isbetter than already existing known drugs and it leads us to believe that, the compounds will possibly be suitable for treatment. 


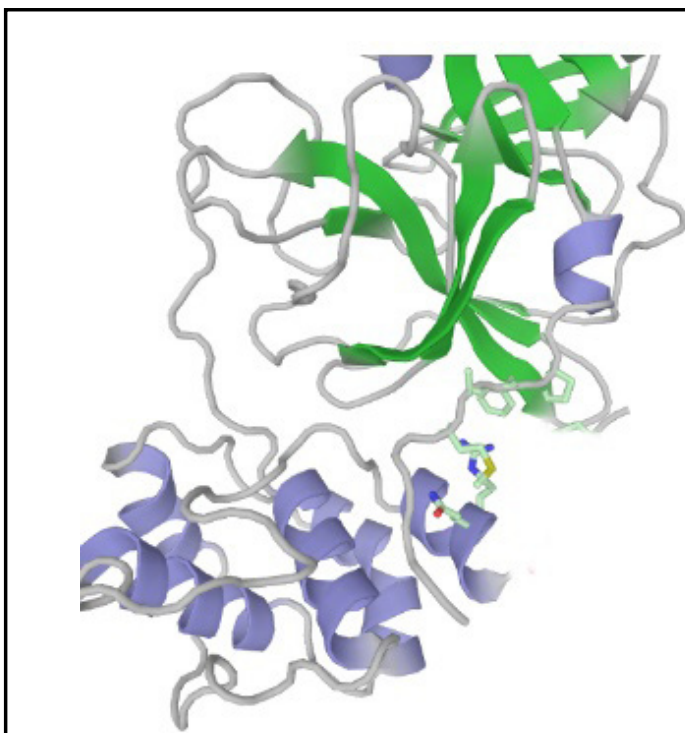

a)

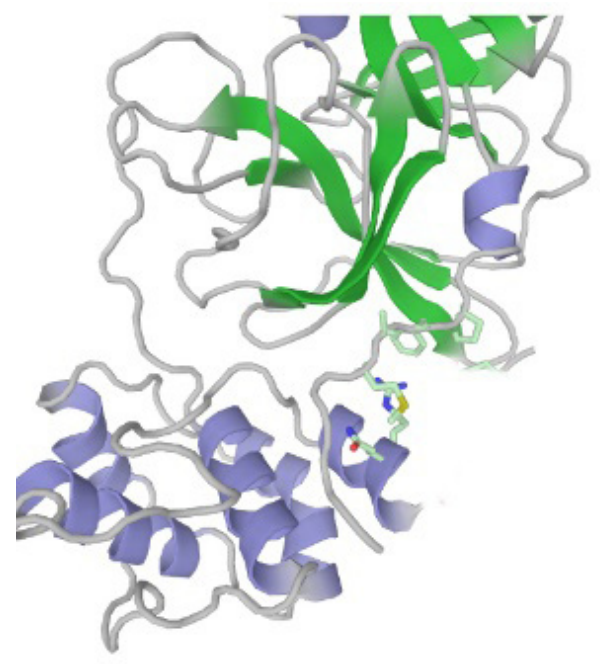

c)

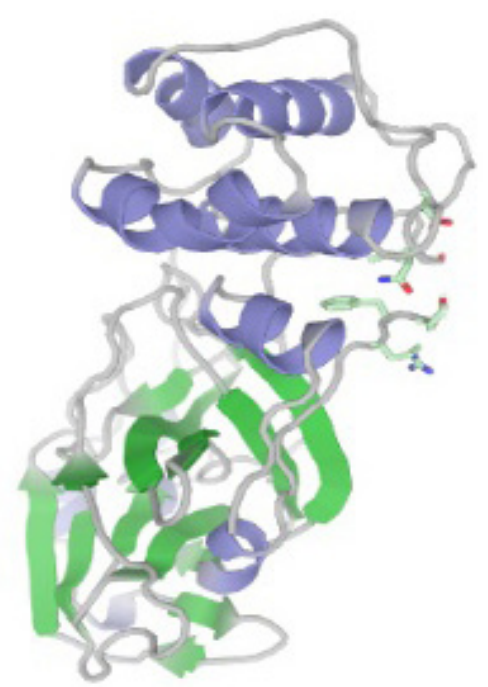

b)

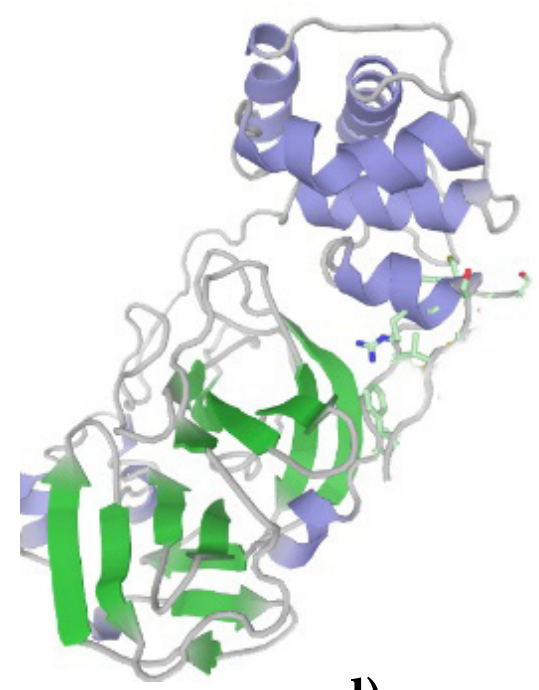

d)

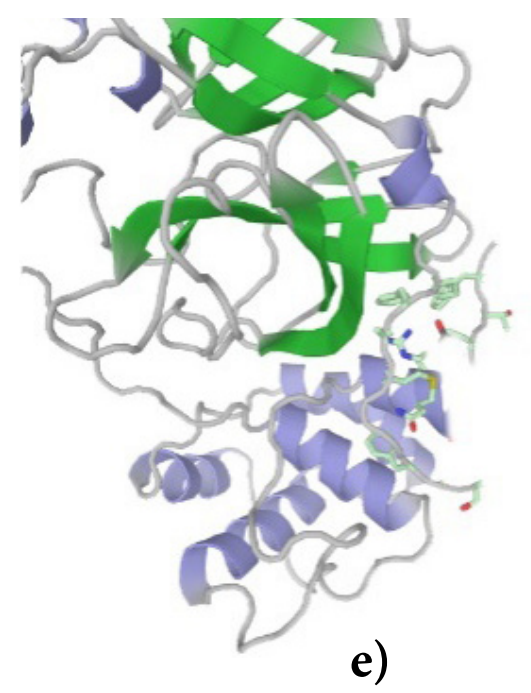

Fig 4: Molecular docking simulation of selected ligands with protease covid-19 a) luteolin b) Apigenin c) Quercetin d) kaempferol e) Benzylglucosinolate. 


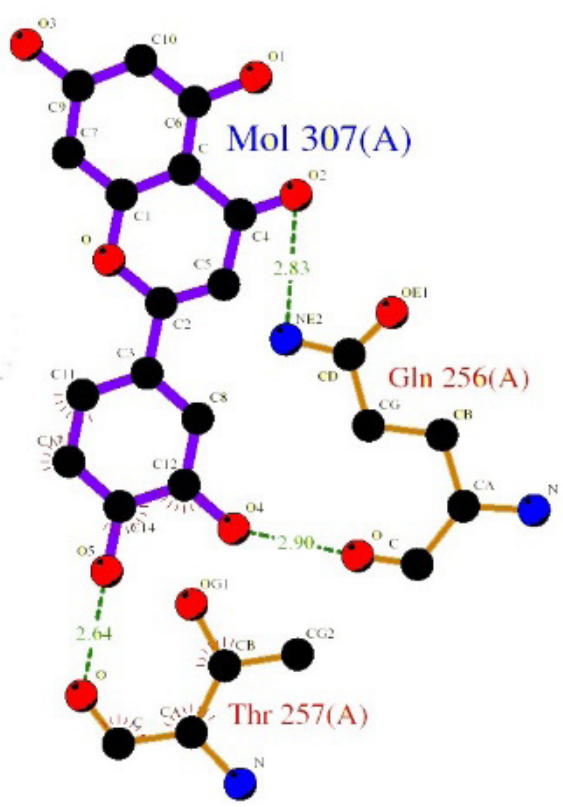

a)

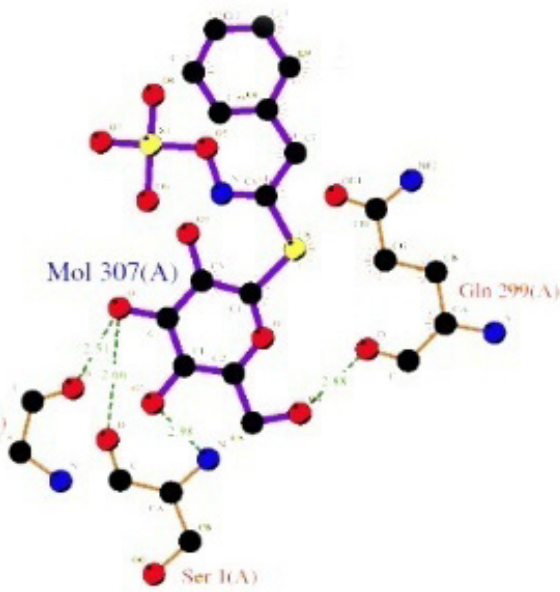

c)

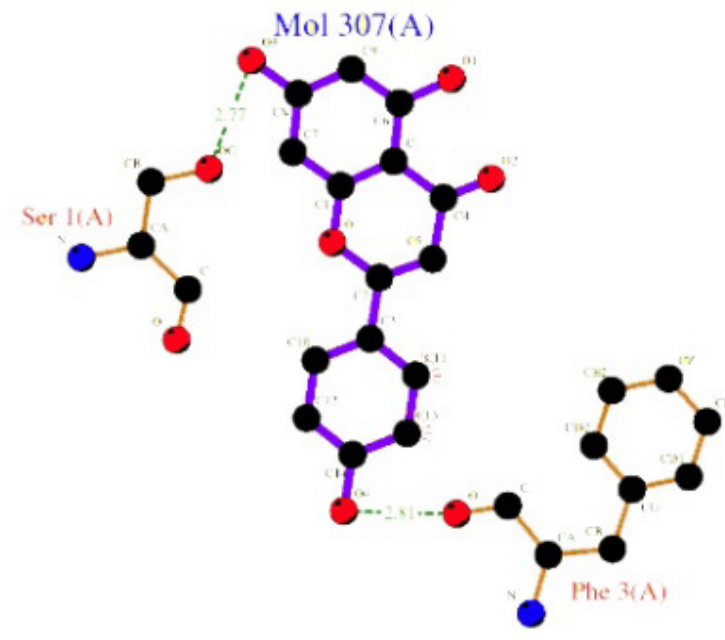

b)

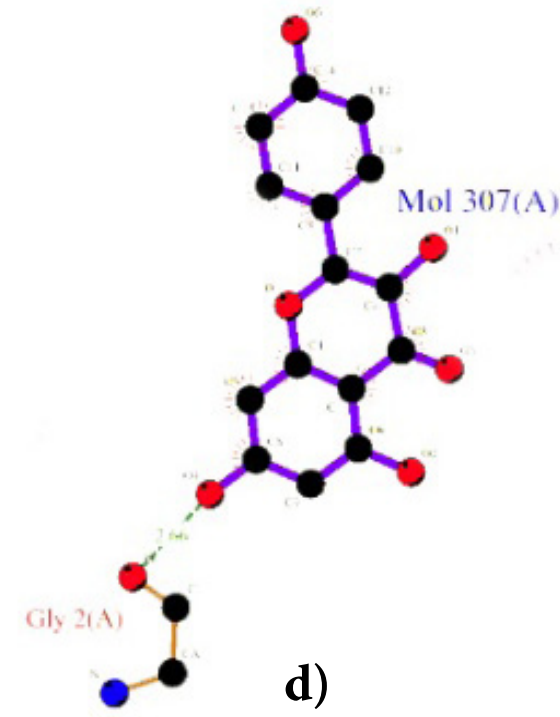

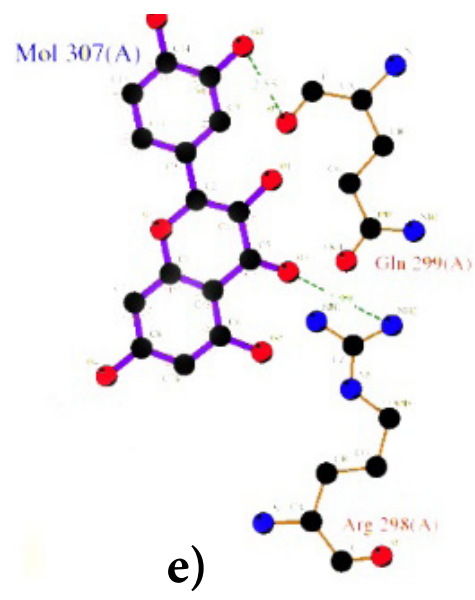

Fig 5: 2-D structures and interaction of compounds a) luteolin b) Apigenin c) Quercetin d) kaempferol e) Benzylglucosinolate. 
Table 3: Docking results

\begin{tabular}{|c|c|c|}
\hline Ligands & Docking score/ binding affinity & Hydrogen bond no. and residues \\
\hline Luteolin & -8.223 & $2 \&$ Gln 256 \&Thr 257 \\
\hline Apigenin & -10.324 & $2 \&$ Ser1 \&Phe 3 \\
\hline Quercetin & -7.241 & $2 \&$ Gln 299 \&Arg 298 \\
\hline kaempferol & -12.435 & $2 \&$ Mol 307 \&Gly 2 \\
\hline Benzylglucosinolate & -15.325 & 4 \& Mol 307 \&Gly 2 \& Ser 1 \& Gln 299 \\
\hline
\end{tabular}

The molecular docking result mentioned in the above tabular column exposed that the selected compounds for molecular docking showed excellent binding affinity when compared to already existing known drugs. Quercetin (-7.241) showed the best binding energy or docking score followed by luteolin (-8.223) and apigenin $(-10.324)$.

\section{Discussion}

Currently, there is no particular vaccine available for the Novel Coronavirus or Covid-19, so we should be acclimatized towards the cure of natural compounds based on aromatic and medicinal plants to having the ability to inhibit COVID19 [10]. By comparing all the compounds studied with the Covid-19 protease basis on the binding energy criteria, knowing that the binding affinity of compound, Quercetin (-7.241) followed by the Luteolin (-8.223) have a good interaction between the receptors and ligands.

From a pharmacological point of view, these two molecules which are proposed as an inhibitor of the coronavirus are molecules having a significant anti-viral efficacy. Previous studies reveal that the presence of flavonoids in the leaves of Carica papaya exhibits potentially anti-dengue activity as noted by the raised platelet numbers. Quercetin is an important compound in Carica papaya Linn., it has the capability to inhibit the replication of viral cells before and after the entry of virions in Vero cells. Luteolin also represents the antiviral and anti-cancer efficacy [27].

According to Lipinski filter parameters and Admet analysis, the compounds (Quercetin and luteolin) are active compounds for different types of models like BBB penetration, P-glycogenic substrate, human intestinal absorption. We suggest that the flavonoid Quercetin and Luteolin of carica papaya might exerts its anti-viral power by blocking the viral assembly mechanism and our results strongly reveals that quercetin and luteolin is a good candidate for the development for effective anti-covid19 compounds. On the whole, we concluded that the flavonoids Quercetin and Luteolin could be investigated in future to be developed as an effective anti-covid19 compound.

\section{Conclusion and Recommendation}

The docking result showed that the Phytoligands present in the leaf of carica papaya Linn against Covid-19 protease (receptor), outcome was vigorously acclamatory. In this study, Phytoligands luteolin and Quercetin and apigenin showed highest docking score and binding affinity. It is concluded that some compounds are perfect or suitable for inhibitory activity on covid-19 through insilico study with special regarding to molecular docking simulation. The present results revealed that two flavonoids compounds i.e. Quercetin and Luteolin have acclamatory binding score and hydrogen bonding and also suitable ADMET analysis. Hence, it has been predicted that the selected compounds except Benzylglucosinolate can possibly refer as a new lead for the treatment of Covid-19 and will be used in future for invivo experiments.

\section{Conflict of Interest:}




\section{References}

[1] World Health Organization (WHO)Laboratory testing of 2019 novel coronavirus (2019-nCoV) in suspected human caseshttps://apps.who.int/iris/handle/10665/330676 (2020)

[2] Richman DD, Whitley RJ, and Hayden FG. Clinical virology. John Wiley \& Sons, 2016

[3] Cui J, Li F, Shi ZL. Origin and evolution of pathogenic coronaviruses. Nat Rev Microbiol. 2019; 17(3):181-192.

[4] Wang D, Hu B, Hu C, Zhu F, Liu X, Zhang J, Wang B, Xiang H, Cheng Z, Xiong Y, Zhao Y, Li Y, Wang X, Peng Z. Clinical characteristics of 138 hospitalized patients with 2019 novel coronavirus-infected pneumonia in Wuhan, China. JAMA. 2020; 323(11):1061.

[5] Chen N, Zhou M, Dong X, Qu J, Gong F, Han Y,Qiu Y, Wang J, Liu Y, Wei Y, Xia J, Yu T, Zhang X, Zhang L. Epidemiological and clinical characteristics of 99 cases of 2019 novel coronavirus pneumonia in Wuhan, China: a descriptive study. Lancet. 2020; 395(10223):507-513.

[6] Song Z, Xu Y, Bao L, Zhang L, Yu P, Qu Y, Zhu H, Zhao W, Han Y, Qin C.From SARS to MERS, thrusting coronaviruses into the spotlight.Viruses.2019; 11: 59.

[7] Wu F, Zhao S, Yu B, Chen YM, Wang W, Song ZG, Hu Y, Tao ZW, Tian JH, Pei YY, Yuan ML, Zhang YL, Dai FH, Liu Y, Wang QM, Zheng JJ, Xu L, Holmes EC, Zhang YZ. A new coronavirus associated with human respiratory disease in China. Nature. 2020; 579(7798): 265-269.

[8] Huang C, Wang Y, Li X, Ren L, Zhao J, Hu Y, Zhang L, Fan G, Xu J, Gu X, Cheng Z, Yu T, Xia J, Wei Y, Wu W, Xie X, Yin W, Li H, Liu M, Xiao Y, Gao H, Guo L, Xie J, Wang G, Jiang R, Gao Z, Jin Q, Wang J, Cao B. Clinical features of patients infected with 2019 novel coronavirus in Wuhan, China. The Lancet. 2020; 395: 497-506.

[9] Zhu N, Zhang D, Wang W, Li X, Yang B, Song J, Zhao X, Huang B, Shi W, Lu R, Niu P, Zhan F, Ma X, Wang D, Xu W, Wu G, Gao GF, Tan W. A novel coronavirus from patients with pneumonia in China, 2019. N. Engl. J. Med., 2020; 382: 727-733.

[10] Chen $\mathrm{Z}$ and Nakamura T. "Statistical evidence for the usefulness of Chinese medicine in the treatment of SARS," Phytother. Res. Int. J. Devoted Pharmacol. Toxicol. Eval. Nat. Prod. Deriv. 2004; 18(7):592-594.

[11] Aruoma OI, Colognato R, Fontana I, Gartlon J, Migliore L, Koike K, Coecke S, Lamy E, Mersch-Sundermann V, Laurenza I, Benzi L, Yoshino F, Kobayashi K, Lee MC. Molecular effects of fermented papaya preparation on oxidative damage, MAP Kinase activation and modulation of the benzo[a]pyrene mediated genotoxicity Biofactors. 2006; 26(2):147159.

[12] Mehdipour S, Yasa N, Dehghan G, Khorasani R, Mohammadirad A, Rahimi R, Abdollahi M.Antioxidant potentials of Iranian Carica papaya juice in vitro and in vivo are comparable to alpha-tocopherol.Phytother Res. 2006; 20(7):591594.

[13] Sadek KM. Antioxidant and immunostimulant effect of Carica papaya Linn. Aqueous extract in acrylamide intoxicated rats. Acta Inform Med. 2012; 20(3):180-185.

[14] Filimonov DA, Lagunin AA, Gloriozova TA, Rudik AV, Druzhilovskii DS, Pogodin PV,PoroikovVV.Prediction of the biological activity spectra of organic compounds using the PASS online webresource. Chem. Heterocycl. Compd. 2014; 50 (3): 444-457.

[15] BermanHM, Westbrook J, Feng J,Gilliland G, Bhat TN, Weissig H,Shindyalov IN, Bourne PE.The Protein Data Bank Nucleic Acids Research, 2000; 28: 235-242.

[16] Miean, K.H., Mohamed, S. Flavonoid (myricetin, quercetin, kaempferol, luteolin, and apigenin) content of edible tropical plants. J. Agric. Food Chem. 2001; 49: 3106-3112.

[17] Canini A, Alesiani D, D’Arcangelo G, Tagliatesta P, Gas chromatography-mass spectrometry analysis of phenolic compounds from Carica papaya L. leaf. J Food Compos Anal. 2007; 20: 584-590

[18] Lim TK, Carica papaya. In: Edible medicinal and non-medicinal plants. Springer 1. 2012; 693-717 
[19] Senthilvel P, Lavanya P, Kumar KM, Swetha R, Anitha P, Bag S, Sarveswari S, Vijayakumar V, Ramaiah S, Anbarasu A. Flavonoid from Carica papaya inhibits NS2B-NS3 protease and prevents Dengue 2 viral assembly. Bioinformation. 2013;9(18): 889-895

[20] Yogiraj V, Goyal PK, Chauhan CS, Goyal A, Vyas B, Carica papaya Linn: An overview. International Journal of Herbal Medicine. 2014; 2(5): 01-08

[21] Marvin View (version 18.10.0) calculation module developed by ChemAxon,http://www.chemaxon.com/products/marvin, 2014.

[22] PyMol - The PyMol Molecular Graphics System, Version 1.3 Schrodinger, LLC.http://www.pymol.org.

[23] Lipinski CA. Lead- and drug-like compounds: the rule-of-five revolution. Drug Discov TodayTechnol. 2005; 1: 337341.

[24] Daina A, Michielin 0, Zoete V. SwissADME: a free web tool to evaluate pharmacokinetics,drug-likeness and medicinal chemistry friendliness of small molecules. Sci Rep. 2017; 7: 42717.

[25] Daina A, Michielin O, Zoete V. SwissADME: a free web tool toevaluate pharmacokinetics, drug-likeness and medicinal chemistryfriendliness of small molecules. Sci. Rep., 2017; 7, 42717.

[26] Dallakyan S, Olson AJ. Small-Molecule Library Screening by Docking with PyRx. Methods Mol Biol. 2015;1263:24350.

[27] Soleymani S, Zabihollahi R,Shahbazi S, and Bolhassani A. Antiviral effects of saffron and its major ingredients. Curr. Drug Deliv. 2018:15(5); 698-704 